\title{
CHANGES OF LIFE EXPECTANCY IN ESTONIA DURING THE LAST 70 YEARS
}

\author{
ENE-MARgit Tirt
}

\begin{abstract}
The life expectation characterises the health conditions, especially mortality of a population at the year of calculation. The changes of life expectancy in time characterise the general health trends of a population. The difference between men's and women's life expectation in Estonia is large, about 9 years, but the difference of remaining lifetime lessens with age. Life expectancy of both men and women has increased quite rapidly during the last decades, also infant mortality has reached the value typical for highly developed countries (40 times lower level than 70 years ago). International forecasts show that Estonians' life expectancy will approach to that of Finns by the end of 21st century.
\end{abstract}

Keywords: life expectancy; population health; infant mortality

Life expectancy is one of the most important and informative demographic characteristics for estimating the health condition of a population. Life expectancy for some fixed age (most often this age has been taken as zero, that is, we speak about the life expectancy at birth) can be calculated for the population if the data on mortality and age-sex distribution exist. Life expectancy characterises the health situation of the population for the fixed year of calculation. Therefore, it is not right to say that, if we calculate the life expectancy at birth today, this means that the child born today will live so long. This statement is true when we add the condition: if mortality will be unchanged during his/her lifetime. Naturally, this condition is not true; in general, mortality is constantly descending, and probably the child will live much longer.

Life expectancy characterises the health conditions, especially mortality, of a population in the year of calculation, briefly - today. Hence, its changes in time characterise the general health trends of a population. 


\section{ESTONIA TODAY}

\section{Life expectancy and remaining lifetime}

Usually, tables of life expectancy demonstrate the average remaining lifetime in years for persons who attain a given age if mortality remains unchanged. It is understandable that the longer person has lived, the shorter is the remaining lifetime for them, but the higher age they will reach; see Figures 1 and 2.

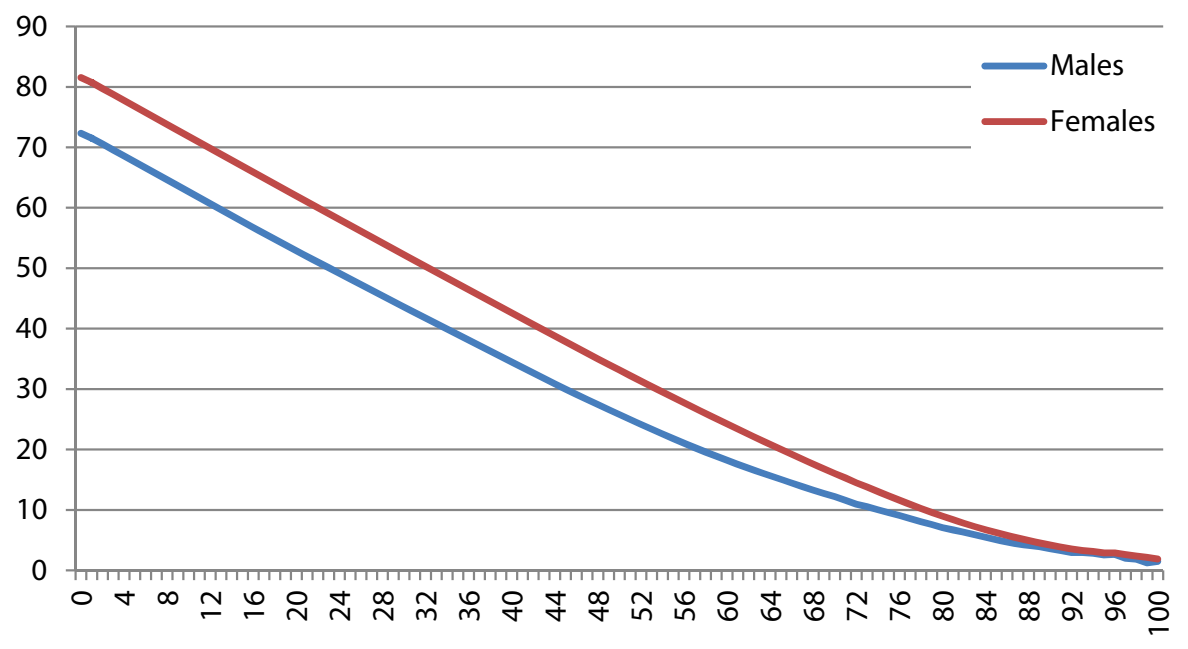

Figure 1. Remaining lifetime for men and women of different ages living in Estonia, 2014.

It is quite enlightening to compare Figures 1 and 2. For instance, a man at the age 60, knowing that men's life expectancy is about 70 years in Estonia, will be gladly surprised seeing from Figure 2 that his expected lifetime is almost 78 years. The same fact is visible in Figure 1 as well, where the expected remaining lifetime is about 18 years.

We can also see that the difference between men's and women's remaining lifetime lessens with age: being more than 9 years at the moment of birth, the difference remains almost at the same level for 20 years. During the following twenty years - from ages 21 to 40 - the difference also changes for less than one year and is more than 8 years for people aged 40. More rapid convergence of men's and women's life expectancy starts in the age-group 50+. For men and women aged $80+$, the difference in expected lifetime is less than two years. 


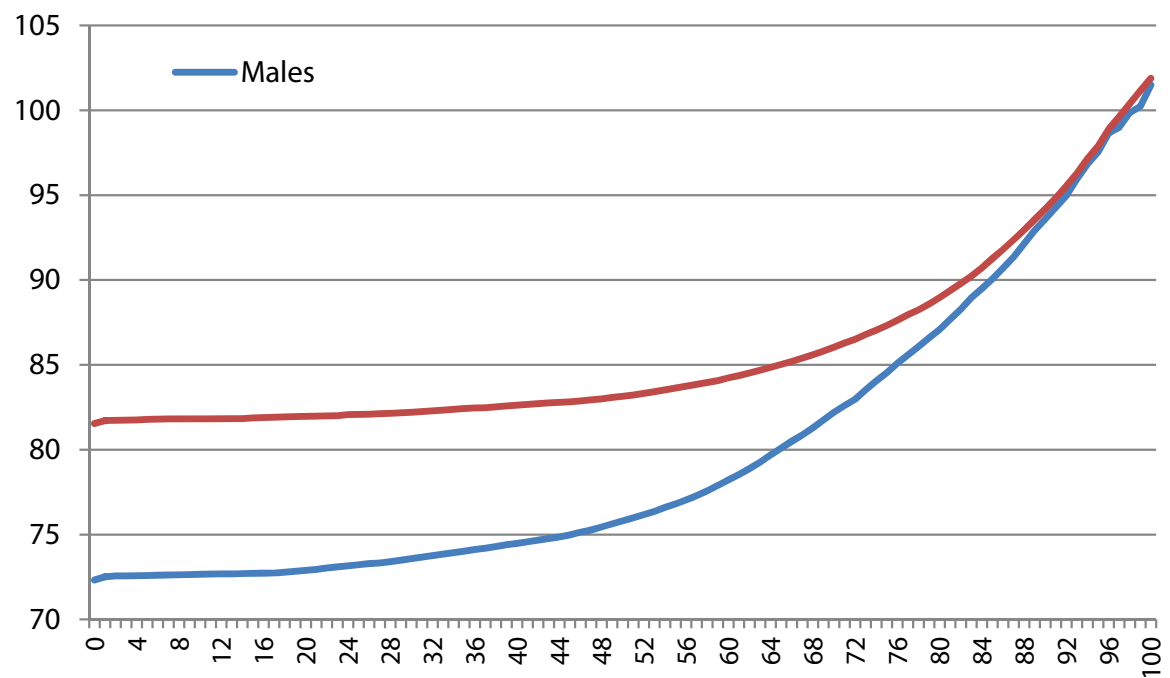

Figure 2. Expected summary lifetime for men and women of different ages living in Estonia, 2014.

\section{Regional differences in life expectancy}

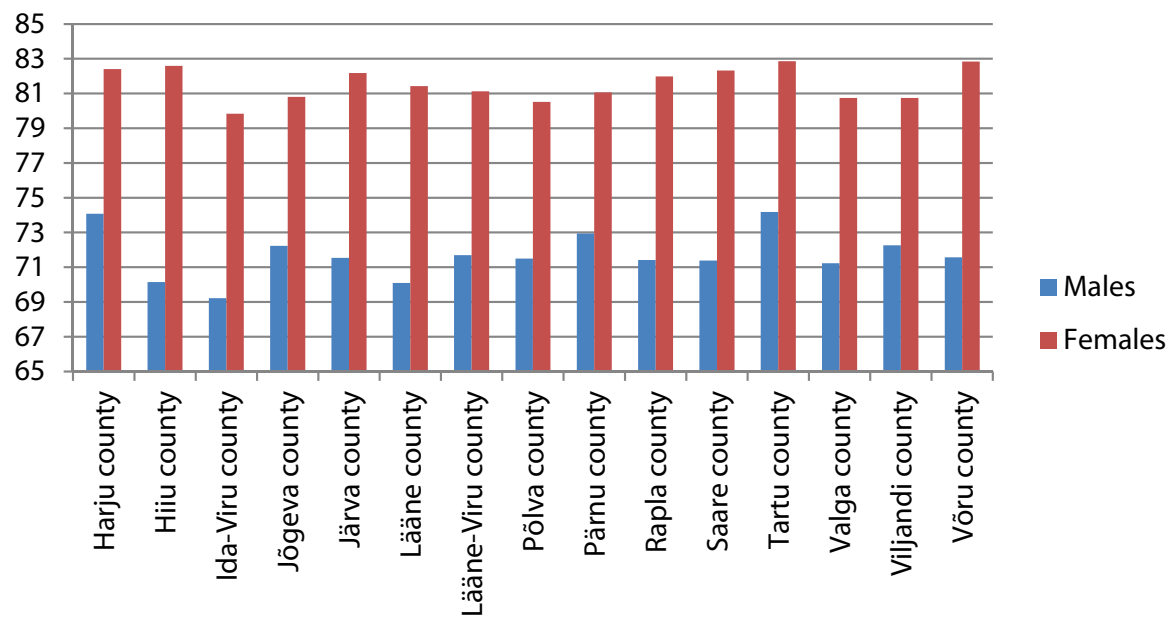

Figure 3. Life expectancy of men and women in different counties of Estonia, data from 2013/2014.

In spite of the fact that Estonian population is quite small, the differences in life expectancy by counties are rather remarkable: for both men and women, 
the difference between the "best" county and the "worst" county is more than three years. What is remarkable - for both men and women, the worst county in terms of life expectancy is Ida-Viru County where the ethnic structure is quite different from other counties; here the share of ethnic Estonians is less than 20\%, while in Estonia as a whole the share of Estonians is almost 70\%. The best county in this sense for both men and women is Tartu County where the population has comparatively high education. The order of other counties is rather random and does not coincide for men and women.

\section{DEVELOPMENT OF LIFE EXPECTANCY IN ESTONIA}

\section{The first year of life and infant mortality}

The most problematic time in a human's life is its beginning and the first year. This time is statistically characterised by infant mortality. Infant mortality has been measured in all countries for a long time, and we have also statistics on infant mortality in Estonia from the time before the Second World War, see Figure 4.

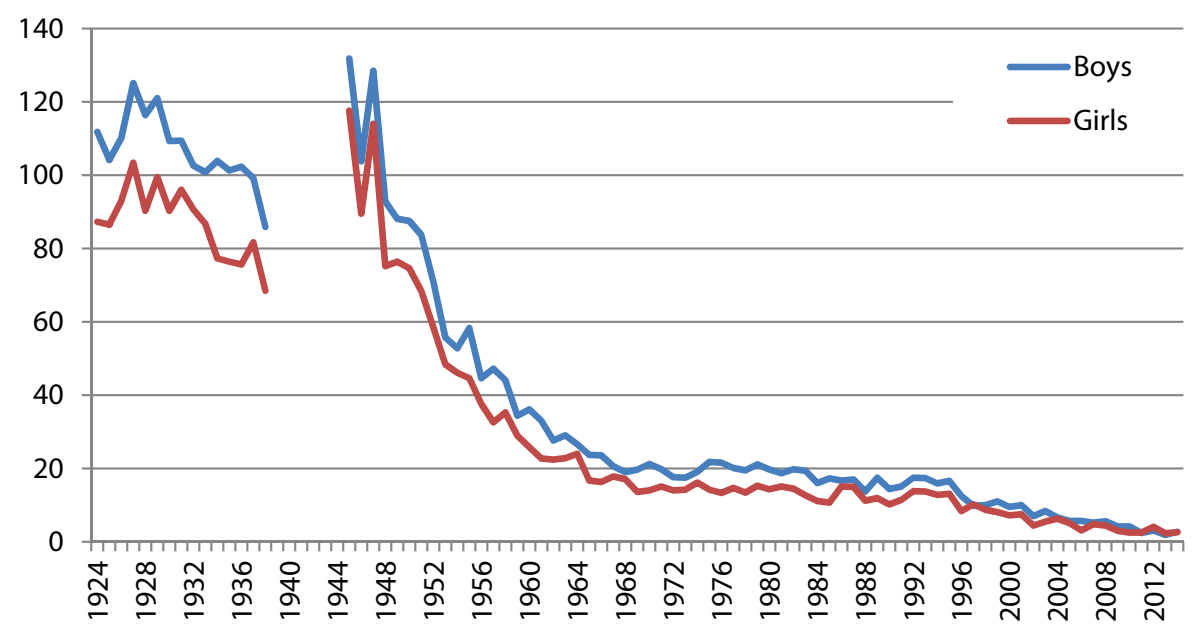

Figure 4. The number of boys and girls who died before their first birthday per 1000 newborn boys and girls.

From Figure 4, we can see that at the beginning of the period, about 90 years, ago infant mortality was quite high, almost $12 \%$ for boys and $10 \%$ for girls. During the less than twenty years in the independent Republic of Estonia, the situation improved markedly; in the late 1930s, boys' mortality was $8.6 \%$ and 
girls' mortality less than $7 \%$ - so the improvement was more than $20 \%$. In the time-series of infant mortality, there is a gap in the years of the first Soviet occupation and the war. After the war, the situation had considerably worsened for boys and girls as well: less than seven out of eight neonates survived the first year. Still, the situation improved rather rapidly and after ten years, by the mid-1950s, infant mortality was almost five per cent for both boys and girls. Reduction of the infant mortality rate continues but with a slackening tempo, and for the last decade of the $20^{\text {th }}$ century the rate was about $1-2 \%$. During the last decade the rate has dropped the level of $0.2-0.4 \%$, which is a good result among all the European countries. Comparing the results of the last three years with the equal after-war period, we can see an improvement of about 40 times.

\section{Life expectancy in Estonia before the Second World War}

Statistical publications issued before the Second World War did not show life expectancy, but it can be estimated using the mortality and census data that were probably of quite a high quality.

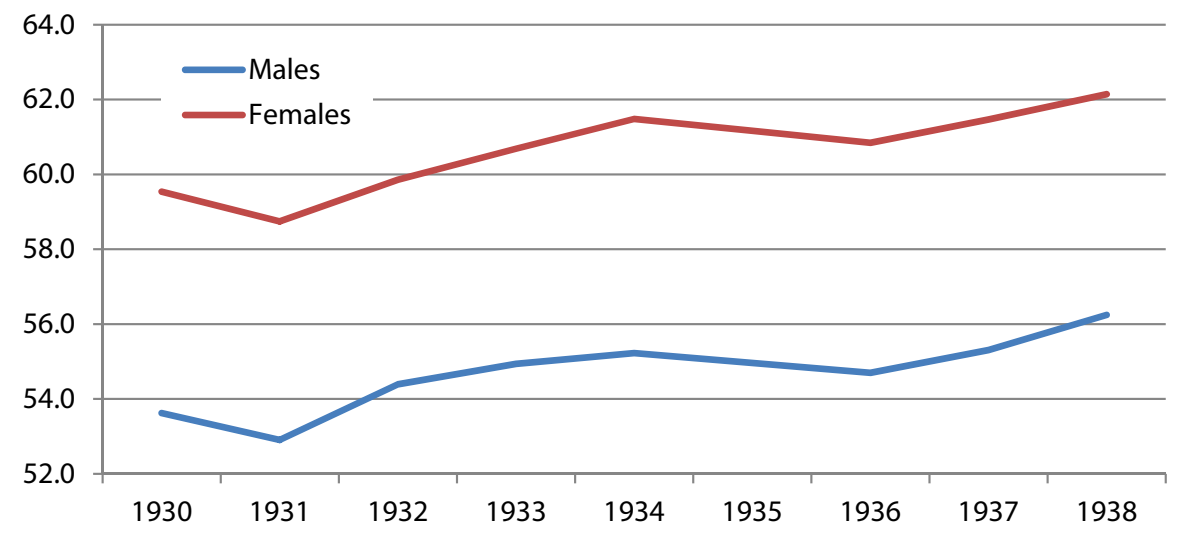

Figure 5. Life expectancy in Estonia before the Second World War.

When we compare the diagrams of remaining lifetime for 2014 and 1929, we can see a big difference. In 1929, the expected remaining lifetime increased in early childhood when the risk of death was the highest. Then more than 1000 newborn boys died before their first birthday. The risk to contract different children's diseases was also high in the following age groups; in the young age, a big risk of death was tuberculosis. The difference between men's and women's life expectancy was quite big in early years but decreased soon and in middle 
age the difference between women and men (3-4 years) was almost twice less than 85 years later, in 2014 .

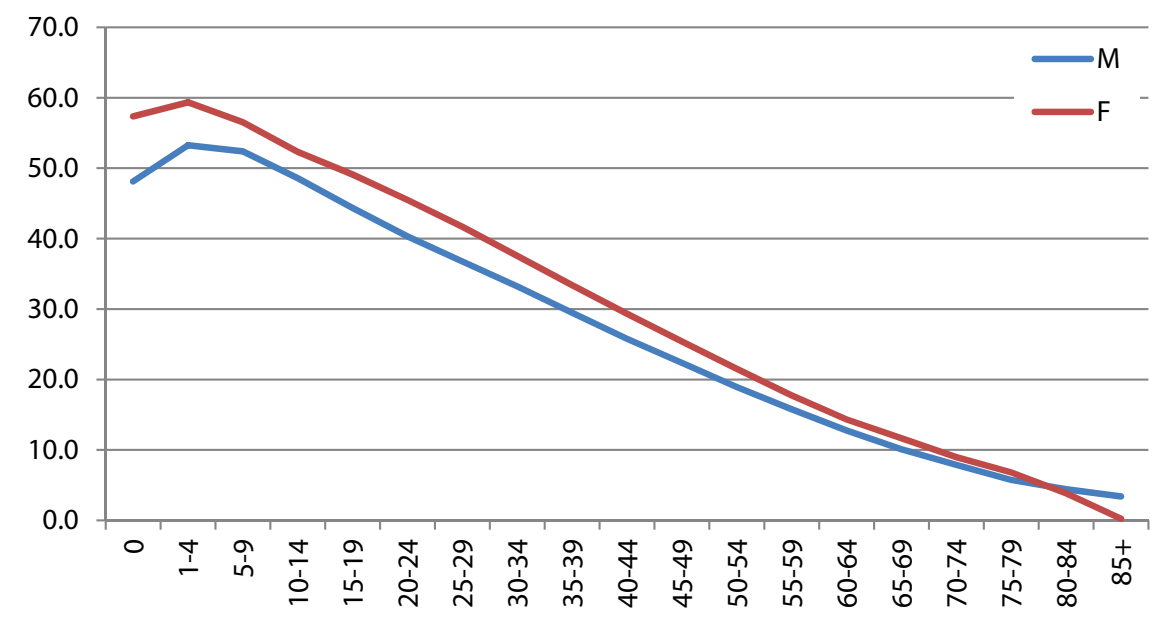

Figure 6. Remaining lifetime for men and women of different ages living in Estonia, 1929.

\section{Trends in life expectancy after the Second World War}

During the war and after it, until the first Soviet census in 1959, there were no demographical data about the population of Estonia. Nevertheless, the UN has calculated life expectancies from the mid- $20^{\text {th }}$ for almost all the countries of the world, including Estonia.

Statistics Estonia has made calculations since the census of 1959, combining in the first twenty-year time period two sequential years for each estimation of data; see Figures 7 and 8.

In Figure 7, the life expectancy data from different sources are combined, and here the trends and stagnation periods are quite well visible. During the first period of independent Estonia, when we have the data of about ten years, the life expectancy of men and women increased by 4 months per year, while the average difference was almost six years in favour of women.

There is no data about the period 1940-1950 and only estimated data for period 1950-1960, when the most rapid increase in life expectancy took place. At this time practical medicine developed very rapidly - antibiotics were taken into every-day use; general vaccination protected children from infectious diseases, as seen from Figure 4. 


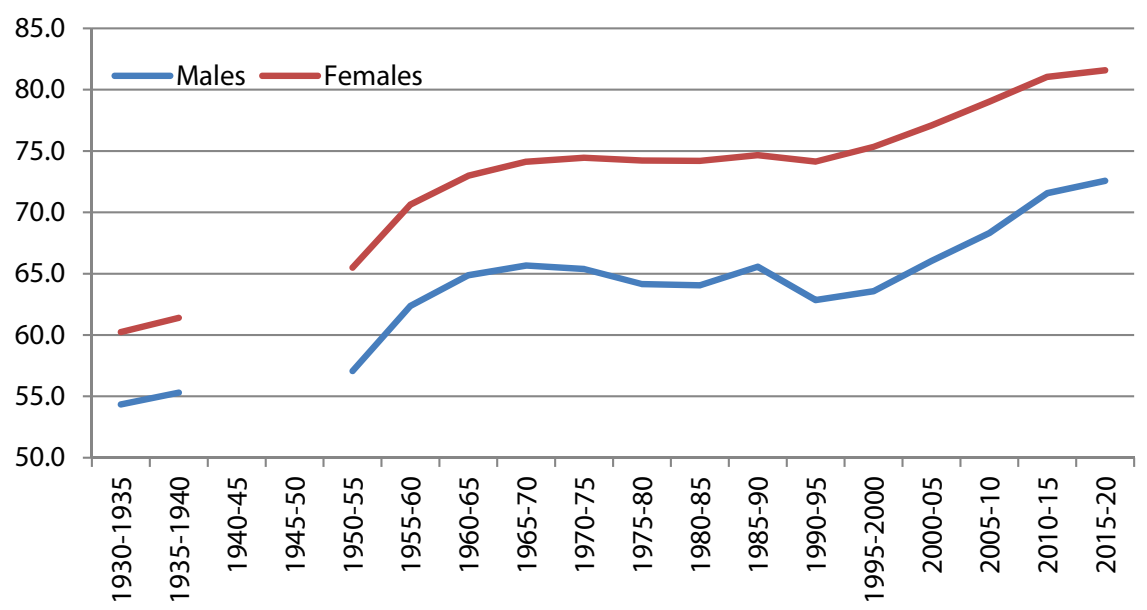

Figure 7. Life expectancy at birth. Combined data for 5-year periods (SA and UN).

The consequent trend can be followed in Figure 8. In the early 1960s, the increase in life expectancy stopped - for men somewhat earlier than for women - and the period of stagnation began that extended for twenty years. Women's life expectancy increased somewhat, men's dropped. In 1983/84, men's life expectancy was 64.41 , that is by 1.19 years less than 20 years ago, and women's life expectancy 74.41 exceeded the level of $1963 / 64$ by 0.9 years.

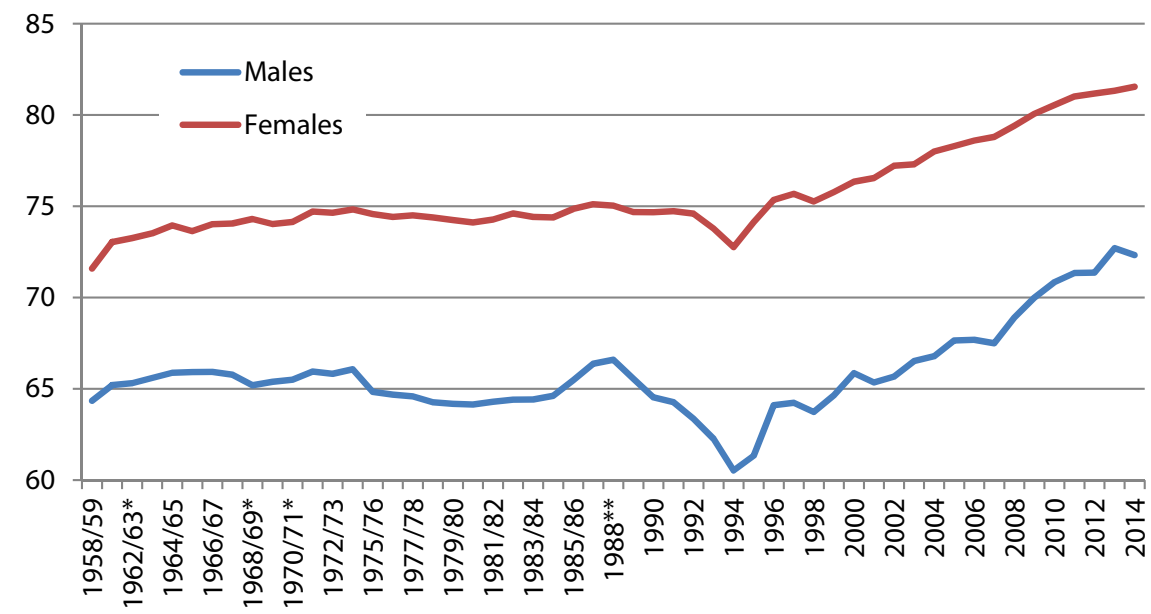

Figure 8. Estimated life expectancy at birth in Estonia. 
An increase in men's life expectancy started in the mid-1980s. Probably this was connected with Gorbachev's prohibition policy. During 1984-1988, men's life expectancy increased by more than two years; for women the increase was about half a year.

After this period, a big downtrend lasting six years started. In 1994 the bottom was reached - men's life expectancy was 60.5 , women's -72.8 years. This can be explained by the so-called transition stress that occurred in all East and Central European countries disengaged from totalitarian regimes. Thereafter, the increasing trend started that during the last decade was also quite rapid in comparison with other countries of the EU. Since 1994, men's life expectancy has increased by almost twelve, women's life expectancy - by nine years. But we are still far from the top countries of Europe and world; see Figure 9. Especially problematic is the big gap among women's and men's life expectancies.

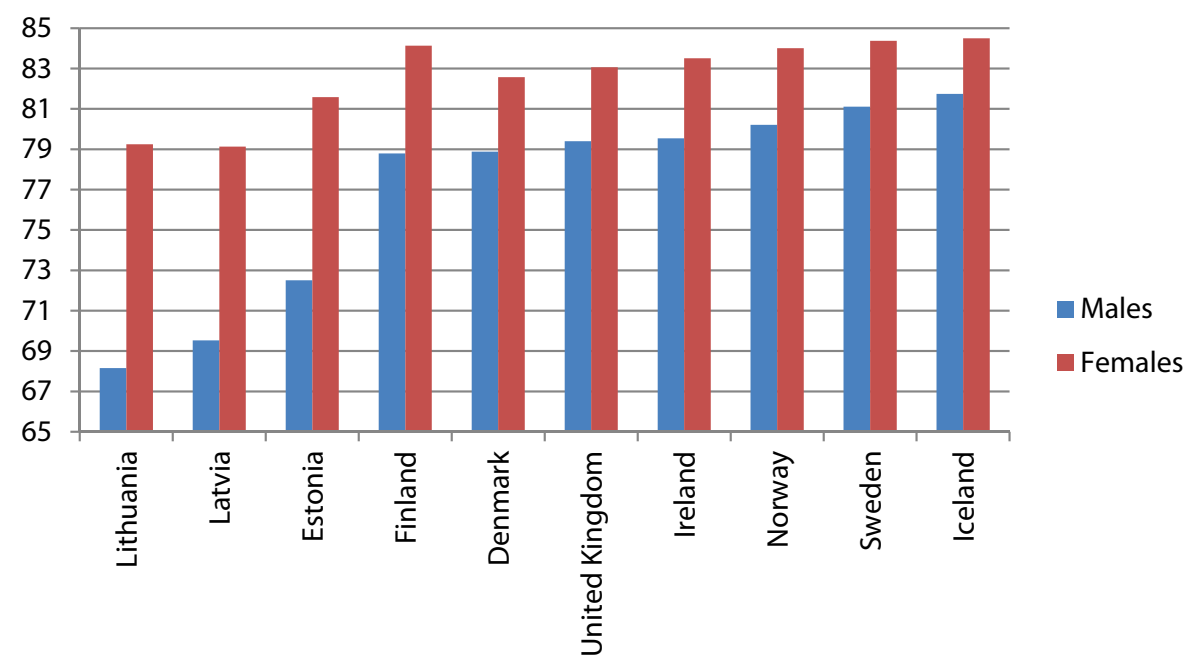

Figure 9. Life expectancy of men and women in the countries of North Europe (UN estimation for 2015-2020, medium variant), ordered by the values of men's life expectancy.

\section{Probable reasons of men's short life expectancy}

It is probable that life expectancy depends on a person's habits and general lifestyle. One of the indicators of lifestyle is education. It is a well-known fact that in Estonia women's level of education is much higher than men's (share of men and women having higher education is correspondingly $24 \%$ and $35 \%$ by census 2011). As the following step, we checked the dependence between the limitations to everyday activities due to health problems and educational level, 
using the data of the census of 2011. The dependence turned out to be quite strong in both men and women, but the differences between genders had almost disappeared. For instance, in Figure 10, we can see that about 10\% of people with higher education have severe problems; among the people with secondary education, the share was $16-17 \%$, and among the people with basic education or less, about $30 \%$ had severe limitations in everyday activities due to health conditions. Naturally, it is not easy to check if low education is caused by poor health or vice versa, but the common connections exist.

The jerk in the curves at the age of 60-64 seems to be connected with the pension age - then the intensity of activities falls, and therefore, in some cases severe limitations do not disturb them anymore.

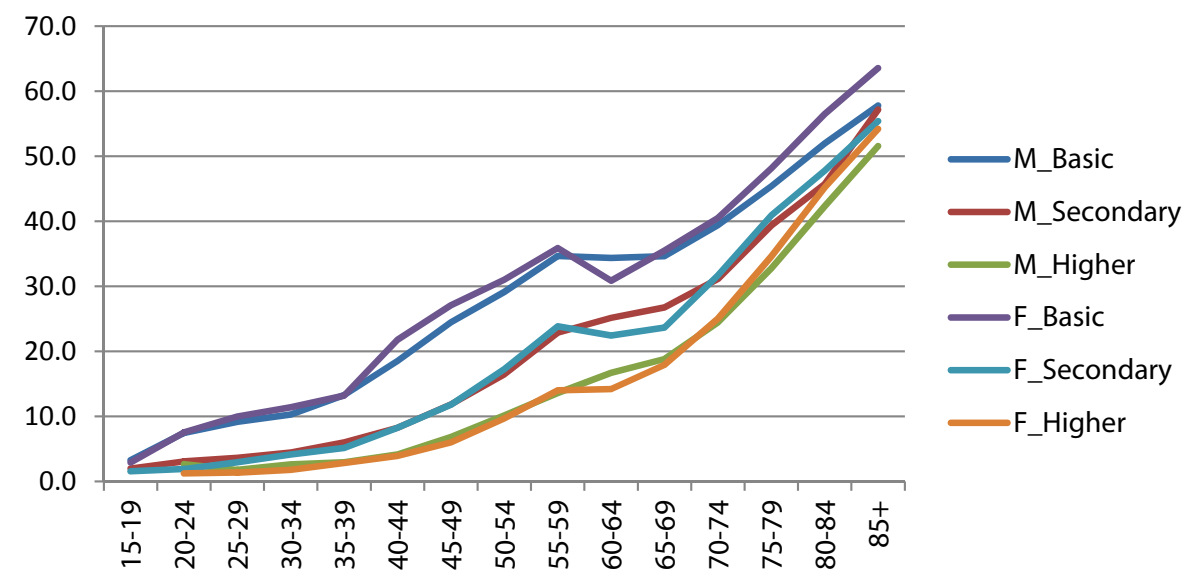

Figure 10. Share of men and women having severe limitations in everyday life due to health problems depending on their age group and educational level.

Using the data of the census of 2011, another characteristic was also calculated; that shows the disability-free life expectancy. It is interesting that the difference between men and women in disability-free life expectancy is not as big as the difference in life expectancy. From here it follows that women spend a longer time from their life being restricted by health conditions than men.

This indicator demonstrates once more that the influence of educational attainment on health is quite strong. Saying robustly: learning a year, you save this year for disability-free life. 


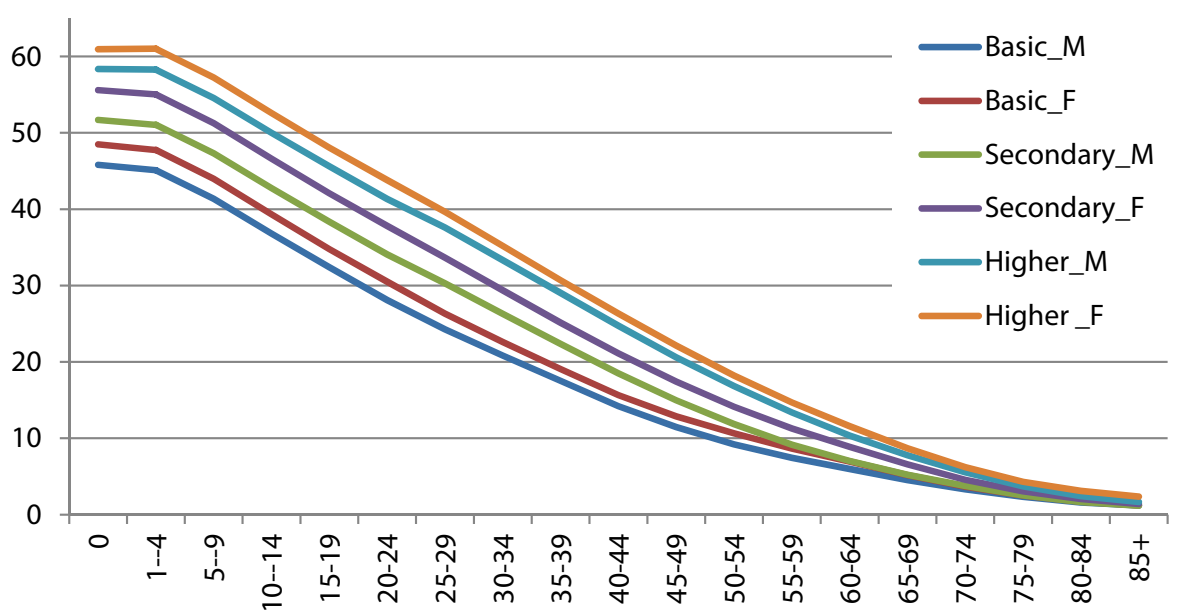

Figure 11. Disability-free life expectancy by sex, age group and educational attainment, data of census 2011.

\section{FUTURE TRENDS IN LIFE EXPECTANCY}

The Population Division of the United Nations prepares population projections for all the countries of the world, using different versions of premises - optimistic, pessimistic, etc. For making projections, some other characteristics should also be forecasted. Figure 12 shows the forecast of life expectancy for Estonian, Swedish, Finnish and Latvian men and women until the year 2100.

In the Figure the differences in development are visible. For the Finnish and Swedish people, the life expectancy of both men and women has been growing, and in the future it will continue in a similar way. In Estonia and Latvia, the curve of life expectancy reflects the intricate course of history of these countries - after recovering from the war wounds, the growth of life expectancy was very fast, but after the growth period, twenty years of stagnation followed in both countries. In both countries, the growth of life expectancy started about five years after gaining independence, and for Estonian men and women it is predicted to be somewhat faster than in Latvia, but the discrepancies between all the countries are diminishing in time, especially in the case of women. So, according to the forecast of the UN, by the end of the century, the life expectancy of Estonian men will be 85 years and of women 90 years, some years more than in Latvia, while Finnish and Swedish women and men will live as long as 90-94 years. It can be hoped that disability-free life expectancy will also grow rapidly, so that our people can enjoy a long and healthy life. 


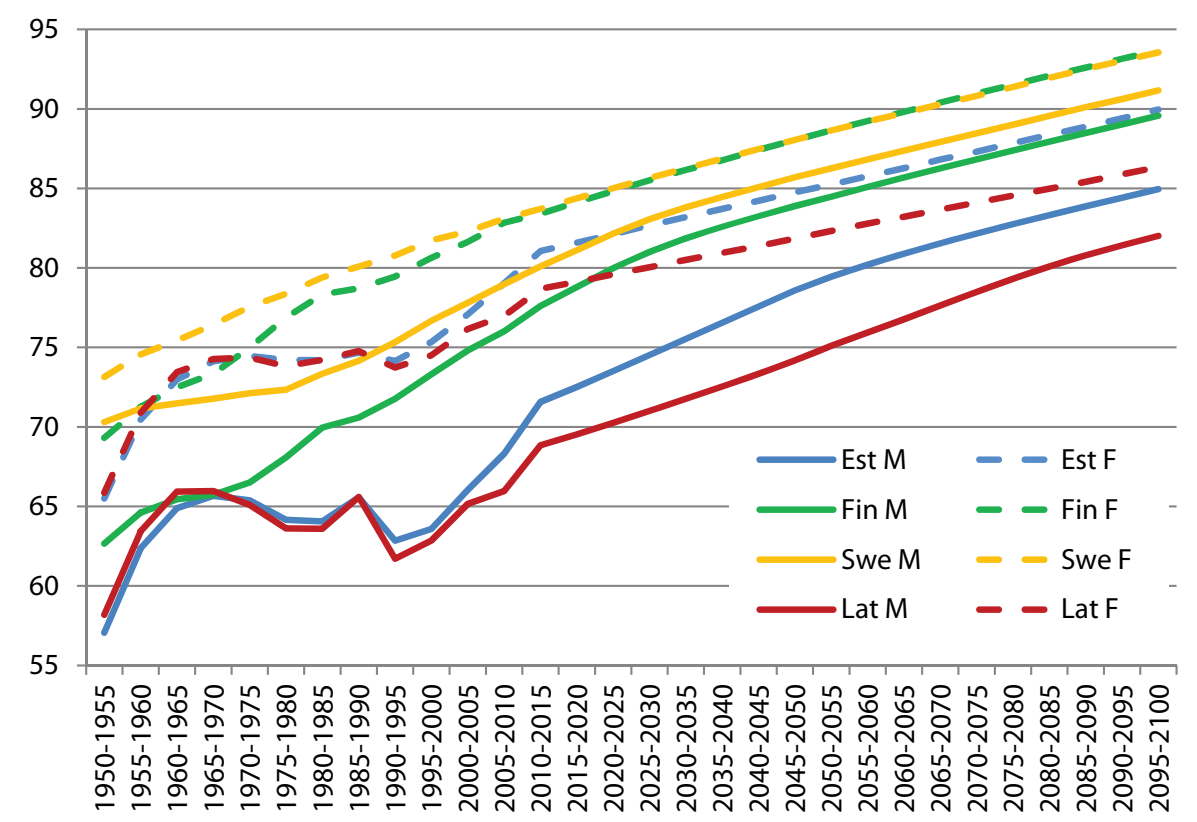

Figure 12. Life expectancy. Estimation, statistics and forecast for Estonia and some close neighbours.

\section{SOURCES}

Statistics Estonia, Statistical Database, http://pub.stat.ee/px-web.2001/dialog/statfile2.asp

United Nations Population Division, http://esa.un.org/unpd/wpp/

\section{Address for correspondence:}

Ene-Margit Tiit

Institute of Mathematical Statistics

Faculty of Mathematics and Computer Science

University of Tartu, Tartu, Estonia

J. Liivi 2-513, 50409 Tartu, Estonia

E-mail: ene.tiit@ut.ee 